\title{
EFFECTS OF DRYING METHODS AND SOLVENTS ON PHENOLIC AND FLAVONOIDS CONTENT, DPPH RADICAL SCAVENGING AND $\alpha$-GLUCOSIDASE ACTIVITIES OF Aquilaria LEAVES EXTRACT
}

\author{
WAN AHMAD WAN-NADILAH ${ }^{1}$, DAILAMI ABDUL GHANI ${ }^{1}$, MUHAMMAD SYAFIQ ABD JALIL ${ }^{1}$, \\ ABDUL MANAF ALI ${ }^{1}$, WAN NUR AMALINA WAN MAMAT ${ }^{2}$ and NOR HASIMA MAHMOD ${ }^{1 *}$ \\ ${ }^{1}$ Faculty of Bioresources and Food Industry, Universiti Sultan Zainal Abidin, \\ 22200, Besut, Terengganu \\ ${ }^{2}$ Centralised Lab Management Centre, Universiti Sultan Zainal Abidin, \\ 22200, Besut, Terengganu \\ *E-mail: norhasima@unisza.edu.my
}

Accepted 10 December 2020, Published online 25 December 2020

\begin{abstract}
Aquilaria is a multipurpose plant with high commercial and medicinal values. The present study aimed to evaluate the effects of drying methods and extraction solvents on the phenolic and flavonoids content in A. malaccensis (AMA), A. subintegra (ASU), and A. sinensis (ASI). Leaf samples were either Air-Dried (AD) or Oven-Dried (OD) and extracted using $100 \%$ Ethanol (EE100), 70\% ethanol (EE70), aqueous (AE), and hexane (HE). There was a significant difference $(p<0.05)$ between the drying methods and the extracting solvents. The OD in AMA leaf samples gave the highest values of total phenolic compounds (TPC) $(52.98$ - $85.15 \mathrm{mg} \mathrm{GAE} / \mathrm{gm})$ and total flavonoid compounds (TFC) $(2180.97-3733.45$ QUE ppm). The highest DPPH radical scavenging was observed in OD-EE70-AMA with the $\mathrm{IC}_{50}$ value of $33.60 \mu \mathrm{g} / \mathrm{mL}$. Meanwhile, OD-EE100-AMA gave the lowest $\mathrm{IC}_{50}$ value $(0.13 \mu \mathrm{g} / \mathrm{mL})$ in the $\alpha$-glucosidase assay, followed by OD-EE70-AMA with $\mathrm{IC}_{50}$ value $0.69 \mu \mathrm{g} / \mathrm{mL}$ with no significant differences among them. OD-EE70-AMA was found to have a higher content of TPC and TFC with the most potent DPPH scavenging and $\alpha$-glucosidase inhibition activities. A strong positive correlation was reported between bioassays and TPC or TFC, hence indicating that AMA leaf used in this study might have the potential as a natural antioxidant and an antidiabetic agent.
\end{abstract}

Key words: $\alpha$-glucosidase activity, Aquilaria sp., DPPH radical scavenging, drying method, solvent extraction

\section{INTRODUCTION}

Aquilaria is an aromatic evergreen tree, belongs to the family Thymelaeceae, which is popularly known as "Gaharu" or "Karas" in Southeast Asia. In Malaysia, native species are $A$. malaccensis, $A$. hirta, A. microcarpa, A. beccariania, and A. rostrata (IUCN, 2015) while A. crasna, A. sinensis, and A. subintegra were originated from Indochina. In this study, A. malaccensis (AMA), A. subintegra (ASU), and $A$. sinensis (ASI) were selected due to easily found in Malaysia (Forestry Department of Peninsular Malaysia, 2016).

In recent years, plants have been extensively studied for their medicinal properties and it is believed that their intake is associated with a

* To whom correspondence should be addressed. reduced risk of degenerative diseases including diabetes (Wan-Nadilah et al., 2019). Many studies proved that diabetes is associated with oxidative stress (Wan-Nadilah et al., 2018) while antioxidants act by inhibiting reactive oxygen species (ROS), eliminating free radicals, or improving antioxidant defenses.

The crucial factor in retaining the biological effect of the plant extract is the drying method. The most preferred techniques were air drying and oven drying due to their easy application and low cost (Kamiloglu \& Capanoglu, 2015). Furthermore, the choice of solvent is another important aspect in ensuring plant extracts of a certain quality and biological activity. Plant's therapeutic value can be easily diminished, hence it is crucial to determine the best solvent for the optimum extraction of the 
bioactive chemical composition. With the above scenario as a background, the present study aims to evaluate the antioxidant and antidiabetic activities as well as total phenolic and flavonoid content of the highlighted plant.

\section{MATERIALS AND METHODS}

\section{Collection of plant material}

The leaf sample of AMA, ASU, and ASI were collected from Forest Research Institute Malaysia (FRIM), Merchang, Terengganu $\left(4^{\circ} 58^{\prime} 58.4^{\prime \prime} \mathrm{N}\right.$ $\left.103^{\circ} 19^{\prime} 19.8^{\prime \prime} \mathrm{E}\right)$, Alor Gajah, Melaka $\left(2^{\circ} 23^{\prime} 03.3^{\prime \prime} \mathrm{N}\right.$ $\left.102^{\circ} 13^{\prime} 10.2^{\prime \prime} \mathrm{E}\right)$ and Seri Kembangan, Selangor $\left(3^{\circ} 00^{\prime} 48.5^{\prime \prime} \mathrm{N} 101^{\circ} 42^{\prime} 12.1^{\prime \prime} \mathrm{E}\right)$, respectively. AirDried (AD) samples were left at room temperature until completely dried while Oven-Dried (OD) samples dried at $40^{\circ} \mathrm{C}$ for $18 \mathrm{hr} /$ until weight constant. The powdered samples were stored at $-20^{\circ} \mathrm{C}$ until further use.

\section{Leaf extract preparation}

The powdered sample was macerated in either $100 \%$ ethanol (EE100) or 70\% ethanol (EE70), distilled water/ aqueous (AE), or hexane (HE) with a ratio of 1:50 (sample: solvents) and sonicated for $20 \mathrm{~min}$. The extraction was repeated three times, then filtered and concentrated in a rotary evaporator (Heidolph, Germany). The crude extracts obtained were stored at $-20^{\circ} \mathrm{C}$ before further use.

\section{Total phenolic content (TPC)}

The TPC was determined by Nasir et al. (2019). The mixture consisted of $10 \mu \mathrm{L}$ extracts or gallic acid, $10 \mu \mathrm{L}$ distilled water, and $100 \mu \mathrm{L} 10 \%$ FolinCiocalteu reagents $(\mathrm{v} / \mathrm{v})$ was incubated for $5 \mathrm{~min}$ in a 96-well plate before being added with $80 \mu \mathrm{L}$ $7.5 \% \mathrm{Na}_{2} \mathrm{CO}$ and further incubated for 30 min under dark conditions. The $765 \mathrm{~nm}$ absorbance was measured and TPC was expressed as GAE/gm extract.

\section{Total flavonoid content (TFC)}

The TFC was determined by Nasir et al. (2019) with minor modification. Mixtures of $25 \mu \mathrm{L}$ sample and $10 \mu \mathrm{L} 5 \% \mathrm{NaNO}_{3}$ were incubated for $6 \mathrm{~min}$ in the dark. Then, $15 \mu \mathrm{L} \mathrm{AlCl}_{3}$ was added and incubated for another $5 \mathrm{~min}$ before $50 \mu \mathrm{L}$ of $1 \mathrm{M}$ of $\mathrm{NaOH}$ was added. The plate was gently shaken for $1 \mathrm{~min}$ and read at $595 \mathrm{~nm}$. TFC was expressed as $\mathrm{mg}$ QE/gm extract.

\section{DPPH free radical scavenging activity}

The antioxidant activity was determined according to Mahmod et al. (2017) with slight modification. About $50 \mu \mathrm{L}$ extracts were mixed with $100 \mu \mathrm{L}$ of $59 \mathrm{mg} / \mathrm{L}$ DPPH. The mixture was left for $30 \mathrm{~min}$ in the dark and read at $570 \mathrm{~nm}$. The percentage of inhibition was then calculated using the following equation: Inhibition $(\%)=[($ A blank $-A$ sample $) /(A$ blank $)] \times 100$. Where; $\mathrm{A}=$ Absorbance.

\section{Alpha-glucosidase inhibition assay \\ This assay was followed by Wan Nadilah et al. (2019) with slight modification. A mixture of $10 \mu \mathrm{L}$ sample, $50 \mu \mathrm{L}$ of phosphate buffer, and 25 $\mu \mathrm{L} \alpha$-glucosidase solution $(0.2 \mathrm{unit} / \mathrm{mL})$ were incubated for $5 \mathrm{~min}$. Then, $25 \mu \mathrm{L}$ of the substrate $(5 \mathrm{mM})$ was added and the reaction was incubated for $30 \mathrm{~min}$. Lastly, $100 \mu \mathrm{L}$ of $0.2 \mathrm{M} \mathrm{Na}_{2} \mathrm{CO}_{3}$ was added to stop the reaction and read at $410 \mathrm{~nm}$. The percentage of inhibition was calculated as follows: Inhibition (\%) $=\left[\left(A_{c}-A_{e}\right) / A_{c}\right] \times 100 \%$. Where; $\mathrm{A}_{\mathrm{c}}$ $=$ difference between the control and blank and $\mathrm{A}_{\mathrm{e}}$ $=$ difference between a sample and blank sample.}

\section{Statistical analysis}

All the experimental data were expressed as mean \pm standard deviation with triplicates. Data were analyzed for one-way ANOVA while the correlation was tested by using Pearson's correlation analysis and differences at $(p<0.05)$ were considered as significant.

\section{RESULTS AND DISCUSSION}

The percentage of yield ranged from 0.82 to $30.82 \%$ (Table 1) with OD had a higher yield compared to $\mathrm{AD}$ for all extracts. This is in agreement with Anwar et al. (2013) which reported that OD extracts produced a higher extraction yield than $\mathrm{AD}$ in cauliflower extract. Moreover, Aquilaria extracted with EE70 showed significantly higher yield compared to EE100, AE, and HE in both drying methods, which indicates yield is parallel with increasing polarity of solvent used. The percentage of yield by species can be reported as ASU > ASI > AMA. It is also shown that the drying method had a significant effect on the extract yield as summarized in Table 1.

Except for AD-EE100-ASI, the OD samples exhibited a higher TPC compared to AD samples. This is congruent with Nik Wil et al. (2014), which reported a higher TPC in OD compared to the AD method in A. malaccensis and tamarind leaves, respectively. Meanwhile, the HE samples exhibited a low TPC in all Aquilaria sp. (Table 2). This might be attributed to hexane itself which is a non-polar solvent that poorly dissolves more polar compounds such as phenolics. The TFC results showed that OD-EE70-AMA has the richest source of flavonoids with 3733.45 que ppm and a significant difference $(p<0.05)$ between all samples. The previous study 
Table 1. Percentage of yield for each drying method and different solvents

\begin{tabular}{ccccc}
\hline \multirow{2}{*}{$\begin{array}{l}\text { Sample using } \\
\text { different solvents }\end{array}$} & Drying Method & \multicolumn{3}{c}{ Yield (\%) (w/v) } \\
\cline { 3 - 5 } & & AMA & ASU & ASI \\
\hline \multirow{2}{*}{ EE100 } & AD & 8.59 & 18.53 & 5.29 \\
& OD & 14.66 & 18.54 & 13.00 \\
\hline \multirow{2}{*}{ EE70 } & AD & 16.93 & 14.70 & 10.51 \\
& OD & 21.32 & 30.82 & 22.35 \\
\hline \multirow{2}{*}{ AE } & AD & 11.24 & 12.71 & 13.83 \\
& OD & 13.50 & 16.21 & 17.72 \\
\hline \multirow{2}{*}{$H E$} & AD & 1.18 & 0.82 & 1.04 \\
& OD & 1.30 & 1.42 & 2.39 \\
\hline
\end{tabular}

EE100 is $100 \%$ Ethanol extract, EE70 is $70 \%$ Ethanol extract, AE is Aqueous extract and $\mathrm{HE}$ is Hexane extract. For the drying method, $A D$ is air drying and $O D$ is oven drying. Meanwhile, the AMA is Aquilaria malaccensis, ASU is Aquilaria subintegra and ASI is Aquilaria sinensis.

by $\mathrm{Fu}$ et al. (2017) towards walnut leaves observed that the optimum yield of flavonoids was obtained from $70 \%$ ethanol and suggested that the flavonoids were highly soluble in ethanol: water mixture. Overall, the effect of drying techniques on TFC showed a similar trend with TPC mainly because flavonoids are also a phenolic compound.

DPPH activity revealed that EE100 and EE70 significantly exhibited lower $\mathrm{IC}_{50}$ values compared to $\mathrm{AE}$ and $\mathrm{HE}$ in both drying methods. The lowest $\mathrm{IC}_{50}$ of $33.60 \mu \mathrm{g} / \mathrm{mL}$ belonged to OD-AMA-EE70. Nopi et al. (2018) stated that the combined use of water and organic solvent might facilitate the extraction of chemicals that are soluble in water or organic solvent. For the OD method, Roshanak et al. (2016) also showed that the DPPH scavenging activity of tea leaves was the highest followed by sun-, fresh-, freeze- and microwave-drying. It is believed that the high TPC might contribute to the high antioxidant activity by high temperature during drying (Lou et al., 2015). Interestingly, the $\mathrm{IC}_{50}$ values for OD-EE70 $(33.60 \mu \mathrm{g} / \mathrm{mL})$, were slightly higher but not significantly different $(p<0.05)$ compared to quercetin $(20.75 \mu \mathrm{g} / \mathrm{mL})$. This clearly shows that the OD-EE70-AMA might be one of the potential resources as a natural antioxidant agent.

Furthermore, all AMA extracts showed $\alpha$ glucosidase inhibition activity with more than $50 \%$ inhibition. The OD-EE100-AMA extract gave the lowest $\mathrm{IC}_{50}$ value of $0.13 \mu \mathrm{g} / \mathrm{mL}$ (Table 2). The study indicated that the more organic solvent system is, particularly the EE100 sample, the more efficient it is in extracting the $\alpha$-glucosidase inhibitors from AMA extract. However, there were no significant differences $(p>0.05)$ detected between the $\mathrm{IC}_{50}$ value of EE100 and EE70. Hence, EE70 was found to be the most preferred extract instead of EE100 because the mixture of ethanol and water has been known as a good solvent for polyphenol extraction due to the different polarity of both solvents, possibility of mixing them in any proportion, and is safe for human consumption (Waszkowiak and Gliszczynska-Swiglo, 2016). Furthermore, the $\mathrm{IC}_{50}$ values of the two extracts were also not significantly different $(p>0.05)$ from that of quercetin and acarbose. Based on these findings, the OD-EE70-AMA was found to be the most promising extraction for study in diabetic animal models which is a huge step in finding alternatives for synthetic drugs that were known for their negative effects.

The analysis showed a positive correlation between the TPC and DPPH scavenging activities $(r=0.796, p<0.05)$. This indicates that the antioxidant activity of Aquilaria sp. extracts could be explained by its phenolic constituents. A similar result was reported by Reihani and Azhar, (2012) suggesting that that the presence of phenolic compounds in Aquilaria sp. leaves extract might be responsible for its antioxidant activity. There is also a positive relationship between TFC and DPPH radical scavenging activities $(r=0.687, p<0.05)$. This is consistent with the previous study by Sariburun et al. (2010). Meanwhile, the relationship between TPC and $\alpha$-glucosidase inhibition property is evident $(r=0.712, p<0.05)$. Meanwhile, $r=0.366$ with $p<0.05$ was recorded for correlation analysis between TFC and $\alpha$-glucosidase activity. The lower correlation could be explained by the fact that there were other non-polyphenolic active compounds such as polysaccharides, which could be contributing to the strong $\alpha$-glucosidase inhibitory activity (Chen et al., 2010). This result indicates that the phenolic content of Aquilaria sp. extracts was responsible for the antioxidant and anti-hyperglycemic activities measured. 


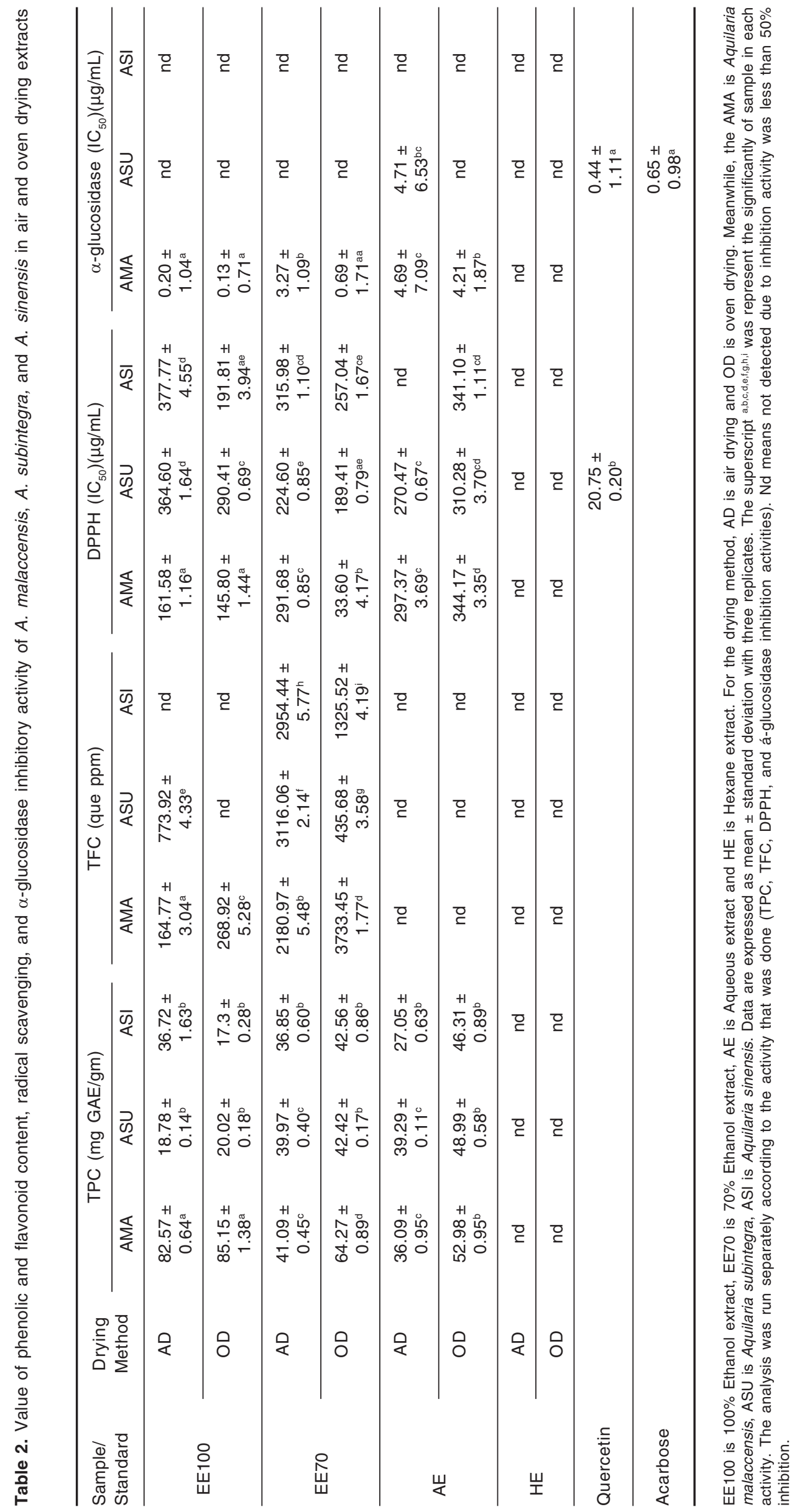




\section{CONCLUSION}

The OD-EE70-AMA was found to be the most preferred extraction due to the high content of TPC and TFC with the most potent DPPH scavenging and $\alpha$-glucosidase inhibition activities. A strong positive correlation was reported between bioassays and TPC or TFC, hence indicating that $A$. malaccensis leaf used in this study might have the potential as a natural antioxidant and an antidiabetic agent.

\section{ACKNOWLEDGEMENTS}

The authors are thankful to the Faculty of Bioresources and Food Industry (FBIM) for laboratory facilities and technical assistance. This work is supported by Universiti Sultan Zainal Abidin (UniSZA) Special Research Grant Scheme (UniSZA/ 2017/SRGS/19).

\section{REFERENCES}

Anwar, F., Kalsoom, U., Sultana, B., Mushtaq, M., Mehmood, T. \& Arshad, H.A. 2013. Effect of drying method and extraction solvent on the total phenolics and antioxidant activity of cauliflower (Brassica oleracea L.) extracts. International Food Research Journal, 20(2).

Chen, H., Lu, X., Qu, Z., Wang, Z. \& Zhang, L. 2010. Glycosidase inhibitory activity and antioxidant properties of a polysaccharide from the mushroom Inonotus obliquus. Journal of Food Biochemistry, 34(1): 178-191.

Forestry Department of Peninsular Malaysia. 2016. Species ladang. URL https://www.forestry.gov. my/index.php/en/species-ladang/ (accessed 09.23.2019).

Fu, J., Xiao, H., Yu, S., Wu, H., Berenjian, A. \& Song, Y. 2017. Response surface optimized ultrasonic-assisted extraction of total flavonoids from walnut leaves and in vitro antibacterial activities. American Journal of Biochemistry and Biotechnology, 13(4): 176-188.

IUCN. 2015. The IUCN Red List of Threatened Species. URL http://www.iucnredlist.org (accessed 10.8.2019).

Kamiloglu, S. \& Capanoglu, E. 2015. Polyphenol content in figs (Ficus carica L.): Effect of sun-drying. International Journal of Food Properties, 18(3): 521-535.

Lou, S., Lai, Y., Huang, J., Ho, C. \& Ferng, L. 2015. Drying effect on flavonoid composition and antioxidant activity of immature kumquat. Food Chemistry, 171: 356-363.
Mahmod, N.H., Johar, A.J., Hamid, M.H.A. \& Ali, A.M. 2017. Comparative assessment of antioxidant activities in Aquilaria malaccensis leaf extracts. Journal of Agrobiotechnology, 8(2): 77-85.

Nasir, N.M., Mohd, K.S., Ibrahim, N., Rodi, M.M.M. \& Zakaria, A.J. (2019). Physicochemical analysis and antioxidant activity of honey from three Malaysian stingless bees species. Journal of Agrobiotechnology, 10(2): 1-11.

Nik Wil, N.N.A., Noor Adila, M.O., Ibrahim, N.A. \& Tajuddin, S.N. 2014. In vitro antioxidant activity and phytochemical screening of Aquilaria malaccensis leaf extracts. Journal of Chemical and Pharmaceutical Research, 6(12): 688-693.

Nopi, N.S., Anwar, E., Nurhayati, T. \& Anwar, E. 2018. Optimization of extraction condition to obtain antioxidant activity and total phenolic content of seagrass Thalassia hemprichii (Ehrenb.) Asch from Indonesia. Pharmacognosy Journal, 10(5): 958-962.

Reihani, S.F.S. \& Azhar, M.E. 2012. Antioxidant activity and total phenolic content in aqueous extracts of selected traditional malay salads (ulam). International Food Research Journal, 19(4): 1439-1444.

Roshanak, S., Rahimmalek, M. \& Goli, S.A. 2016. Evaluation of 7 different drying treatments in respect to total flavonoid, phenolic, vitamin $\mathrm{C}$ content, chlorophyll, antioxidant activity, and color of green tea (C. sinensis or C. assamica) leaves. Journal of Food Science and Tech, 53(1): 721-729.

Sariburun, E., Şahin, S., Demir, C. \& Uylaşer, V. 2010. Phenolic content and antioxidant activity of raspberry and blackberry cultivars. Journal of Food Science, 75(4): 328-335.

Wan-Nadilah W.A., Akhtar, M.T., Shaari, K., Khatib, A., Hamid, A.A. \& Hamid, M. 2019. Variation in metabolites and $\alpha$-glucosidase inhibitory activity of Cosmos caudatus at different growth stages. BMC Complementary and Alternative Medicine, 19: 245.

Wan-Nadilah, W.A., Khozirah, S., Khatib, A., Hamid, A.A. \& Hamid, M. 2018. Evaluation of the $\alpha$-glucosidase inhibitory and free radical scavenging activities of selected traditional medicine plant species used in treating diabetes. International Food Research Journal, 26(1): 75-85.

Waszkowiak, K. \& Gliszczynska-Swiglo, A. 2016. Binary ethanol-water solvent affect phenolic profile and antioxidant capacity of flaxseed extracts. Eur Food Research and Technology, 242(5): 777-786. 
